This item was submitted to Loughborough's Research Repository by the author.

Items in Figshare are protected by copyright, with all rights reserved, unless otherwise indicated.

\title{
The activity of signal crayfish (Pacifastacus leniusculus) in relation to thermal and hydraulic dynamics of an alluvial stream, UK
}

PLEASE CITE THE PUBLISHED VERSION

http://dx.doi.org/10.1007/s10750-013-1708-1

\section{PUBLISHER}

(c) Springer Verlag

\section{VERSION}

AM (Accepted Manuscript)

\section{PUBLISHER STATEMENT}

This work is made available according to the conditions of the Creative Commons Attribution-NonCommercialNoDerivatives 4.0 International (CC BY-NC-ND 4.0) licence. Full details of this licence are available at: https://creativecommons.org/licenses/by-nc-nd/4.0/

\section{LICENCE}

CC BY-NC-ND 4.0

\section{REPOSITORY RECORD}

Johnson, Matthew F., Stephen P. Rice, and lan Reid. 2019. "The Activity of Signal Crayfish (pacifastacus Leniusculus) in Relation to Thermal and Hydraulic Dynamics of an Alluvial Stream, UK". figshare. https://hdl.handle.net/2134/16418. 
The activity of signal crayfish (Pacifastacus leniusculus) in relation to thermal and hydraulic dynamics of an alluvial stream, UK.

Matthew F Johnson ${ }^{1}$, Stephen P Rice ${ }^{1}$, Ian Reid ${ }^{1}$

${ }^{1}$ Department of Geography, Loughborough University, Loughborough, Leicestershire, LE11 1HB, UK

Corresponding author: Matthew F. Johnson

M.F.Johnson@lboro.ac.uk

+44 (0)1509 222798

Keywords: Radio telemetry, Quantile regression, Invasive species, Passive Integrated Transponder 


\begin{abstract}
Signal crayfish (Pacifastacus leniusculus) are an invasive species of global significance because of their detrimental impacts on freshwater environments and native organisms. The movement of signal crayfish was continuously monitored for 150 days through a $20 \mathrm{~m}$ reach of an alluvial stream in the United Kingdom. PIT-tags were attached to crayfish, allowing their location to be monitored relative to 16 antennae which were buried beneath the river bed. The activity of crayfish was related to water depth and temperature, which were continuously monitored within the instrumented reach. Crayfish were highly nocturnal, with less than $6 \%$ of movements recorded during daylight hours. Activity declined from September and was minimal in November when water temperature was low and flow depth was high. However, relations between environmental parameters and crayfish activity had poor explanatory power which may partly reflect biological processes not accounted for in this study. Water depth and temperature had a limiting relationship with crayfish activity, quantified using quantile regression. The results extend existing data on signal crayfish nocturnalism and demonstrate that, although signal crayfish can tolerate a range of flows, activity becomes limited as water temperature declines seasonally and when water depth remains high in autumn and winter months.
\end{abstract}




\section{Introduction}

An understanding of the timing and controls on the movement and other activity of alien animals is of fundamental importance for understanding their invasions and in attempting to mitigate detrimental impacts. Crayfish are ecologically dominant in many streams because they break down organic matter, can occur in high densities, grow to large body size and are relatively long-lived (Momot, 1995; Nyström et al., 1996; Schofield et al., 2001). As a result, they can be particularly damaging to populations of other organisms when introduced outside their native range (Lodge et al., 1998; Gherardi et al., 2006). The signal crayfish (Pacifastacus leniusculus) is native to northwest North America, but, due to introductions by humans, is now widespread as an invasive species in Europe, Japan and other regions of North America, including California (Machino \& Holdich, 2005). Signal crayfish have had substantial, deleterious impacts where introduced, including the destruction of macrophyte stands, the impoverishment of macroinvertebrate fauna and the exclusion of juvenile fish and other crayfish species through predation and competition (Nyström \& Strand 1996; Guan \& Wiles, 1997; Vorburger \& Ribi, 1999; Usio et al., 2001; Stenroth \& Nyström, 2003; Crawford et al., 2006). Signal crayfish have also spread a disease to which they are largely immune, but to which the only native crayfish species, the white-clawed crayfish (Austropotamobius pallipes), is highly susceptible (Holdich et al., 1999). As a result of these impacts, white-clawed crayfish in the UK are being replaced by signal crayfish across their native range (Almeida et al., 2013) and are therefore listed as endangered and legally protected. Signal crayfish also have the potential to alter the physical environment of streambeds through their activity, destabilising river banks and bed sediments (Guan, 1994; Johnson et al., 2010, 2011; Harvey et al., 2011; in press). 
Despite the significance of signal crayfish, little is known of the temporal pattern of their activity or of environmental controls on their daily movement. Crayfish activity has been shown to vary seasonally, with declining movement related to decreases in water temperature. For example, Bubb et al. (2004) found that the movement of radio-tagged signal crayfish in upland rivers in the UK was significantly correlated with water temperature. Increases in discharge also impact crayfish movement and other activity. Robinson et al. (2000) found two out of five radio-tagged white-clawed crayfish (Austropotemobius pallipes) dead after high flow events and others have found crayfish fatalities following floods (Momot, 1966; Royo et al., 2002; Parkyn \& Collier, 2004). Light (2003) recorded smaller signal crayfish populations following spates in upland rivers of the Truckee River catchment, California, USA. Others have suggested that, although crayfish movements are affected by high flows, they are capable of finding refuge during an event and re-emerge afterwards. For example, Bubb et al. (2004) noted that signal crayfish stopped moving during high flow events and resumed moving once flood levels had dropped. Signal crayfish and many other crayfish species have been found to move preferentially at night (Guan, 1994; Guan \& Wiles, 1998; Gherardi et al., 2000; Nyström, 2005). Much of this research comes from markrecapture and baited trapping studies, which are not suited to high resolution (sub-daily) studies of the temporal activity of animals. More recent studies that have utilised radiotelemetry also support nocturnalism in crayfish (Robinson et al., 2000; Bubb et al., 2002).

In this study, radio-telemetry was used to obtain a high temporal resolution record of crayfish movement in a river reach in the United Kingdom and to relate recorded movement patterns to environmental characteristics. The specific aims were to test or confirm that signal crayfish are more active at night than during daylight hours, that signal crayfish are more active in warmer water than colder and that signal crayfish activity is limited during high flow events 
Materials and Methods

Site description

Crayfish activity was recorded for 150 days from $26^{\text {th }}$ June to $22^{\text {nd }}$ November 2009 in the River Bain, Lincolnshire, UK. The river is a small, lowland, alluvial stream with a predominantly gravel substrate, with isolated cobbles and a sand-silt matrix. The catchment upstream of the experimental reach is approximately $63 \mathrm{~km}^{2}$ and lies over Cretaceous chalk with surficial deposits of Pleistocene till. Crayfish were tracked in a $20 \mathrm{~m}$ long, $4 \mathrm{~m}$ wide meandering reach near Biscathorpe $\left(0^{\circ} 09^{\prime} 41^{\prime}\right.$ ' W, $\left.53^{\circ} 20^{\prime} 15^{\prime \prime} \mathrm{N}\right)$, that is surrounded by riparian, cattle-grazed grassland with isolated broadleaf deciduous trees. The reach has a long-established population of signal crayfish, introduced in the 1970s to a pond in the catchment and now occurring in high densities throughout the River Bain. Densities of juveniles and adults exceed 10 ind. $/ \mathrm{m}^{2}$ in some parts of the river (pers.com. D. Holdich). A $10 \mathrm{~m}$ long reach of the channel was instrumented for this study. The morphology of this reach is typical of meander bends in small alluvial rivers. A comparatively steep, straight, coarsegrained glide flows into a leftward-swinging meander bend, the deep thalweg of which is closer to the right bank. This outside bank is steep but the adjacent channel bed is complex due to the slumping of cohesive bank material. Five to eight crayfish burrows were present in this region for the duration of the study. Crayfish burrows were also evident along the river length, but crayfish were mostly observed using coarse grains and marginal macrophyte stands as shelter during the study period. The inner bank is a fine-grained point bar which grades downstream into an open-framework gravel riffle that crosses the channel and is succeeded by a rightward swinging meander, where patterns of flow and cross-stream topography are more or less reversed (Figure 1). 


\section{Environmental variables}

Water temperature was recorded continuously using a thermistor located below the lowest water line on the right bank of the upstream meander bend and marks the downstream limit of instrumentation. A data logger recorded mean temperature every 10 minutes. A pressure transducer at the same location recorded water depth every 10 minutes. Depth information was obtained so that an assessment could be made between crayfish activity and changing river stage. The River Bain is gauged by the Environment Agency of England and Wales (EA) $5 \mathrm{~km}$ downstream from the field site and there are no significant tributaries or abstractions between the study reach and the gauging station. By relating the gauging station data with those of the local pressure transducer during the study period, it was possible to synthesize a longer-term record of flow depth for the study site, making assumptions that channel geometry has not materially changed. Nocturnalism of crayfish was studied by relating animal movements to hours of darkness, determined to be those between sunset and sunrise. By this definition, the hours of darkness change seasonally.

PIT tagging and data collection The activity of crayfish was monitored by tracking individual animals using Passive Integrated Transponder (PIT) tags. PIT telemetry is a passive form of radio-tagging that is increasingly used in ecological research because recovery rates are high (95-100\%), as is reading accuracy (100\%; Gibbins \& Andrews 2004). PIT tags are attached to an object or organism and are located using an antenna (usually within a range of approximately $1 \mathrm{~m}$ ). Antennae can be manufactured in a variety of forms depending on the application. In this study, 16 circular antennae ( $0.25 \mathrm{~m}$ diameter) were buried just beneath the bed surface of the study reach. Every time a tagged crayfish walked over an antenna, a reading was logged. Readings consist of a time and date 'stamp', the antenna ID and the ID of the tag attached to 
the crayfish. The detection range of the antennae used in this experiment was approximately $100 \mathrm{~mm}$ above the antenna, but only $20 \mathrm{~mm}$ from the antenna edge in a horizontal direction. Consequently, a reading indicates a tagged crayfish was present within a circle with a maximum diameter $0.29 \mathrm{~m}$ centred on the antenna. Antennae were connected to a multi-point decoder (MPD) that identified any PIT tags within the detection range of each antenna and logged them. The MPD interrogated the 16 antennae sequentially in a 3 second cycle. This rapid interrogation removed potential issues of interference between antennae positioned close together. It is unlikely a crayfish could cross an antenna within 3 seconds because of their relatively slow walking speed and, therefore, it is unlikely that the interrogation cycle led to missed contacts. All PIT items and tags were purchased from Wyremicrodesign Ltd.

A filter algorithm built into the logging system allowed a distinction to be made between in situ and ex situ crayfish movements. If a crayfish was recorded consecutively by every 3 second cycle in a 30 second period (i.e. 10 times) the activity was termed in situ and revealed a stationary crayfish or movement within the circumference of the antenna interrogation area. When crayfish did not trigger the same antenna consecutively, the reading was considered ex situ and indicated that the crayfish had moved across an antenna without remaining in that area for more than 30 seconds. Ex situ activity includes the possibility that a crayfish moved off, and then back onto the same antenna. Although the presence of multiple tags should not affect the ability of an antenna to record the presence of another tagged crayfish, the presence of a large number of tags on the same antennae at the same moment could lead to missed recordings. To minimise the possibility of incorporating errors introduced by such events, we only analyse ex situ data in this paper. Moreover, this approach ensures a fairly rigorous definition of activity: although in situ readings indicated that a crayfish had moved out onto the channel bed rather than remaining in a burrow or other refuge, this action represents 
significantly less activity than journeys across the channel bed. The activity of crayfish was therefore parameterised by cumulating the total number of ex situ recordings made by all crayfish in the reach across all antennae for each day and dividing the total by the number of crayfish that were active within the reach that day.

The sixteen antennae were distributed non-uniformly through the study reach in association with discrete substrate patches because an ancillary aim of this work (not reported here) was to examine the differential use of different substrate patches by crayfish. Patches were defined and distinguished by grain-size characteristics, macrophyte presence and flow conditions (Figure 1). Antennae are not equidistant and, therefore, movements between different pairs of antennae represent displacements of different lengths. Crayfish activity was therefore also parameterised by distance moved, based on the measured lengths of straight line paths between consecutively triggered pairs of antennae. Actual journey paths are not known, but, because the start and end points are defined, minimum displacement distances can be calculated. An average was again obtained by dividing the total distance moved by all crayfish each day by the number of crayfish active that day. This provides the average distance moved by all active crayfish each day.

\section{Crayfish tagging procedure}

Crayfish remained in the instrumented river reach for a mean period of 11 days (S.D. $=9$ days), after which, they left the reach and rarely returned. This is consistent with previously described nomadic behaviour of both signal crayfish (Bubb et al., 2002; 2004, Light, 2003) and other crayfish species (Gherardi et al., 1998; Schütze et al., 1999; Gherardi et al., 2000; Robinson et al., 2000). To maintain the stock of PIT-tagged crayfish within the instrumented reach, animals were tagged and released throughout the tracking period. On average, five 
PIT-tagged individuals were tracked in the reach each day (S.D. = 3). Crayfish were caught within 20 m upstream and downstream of the instrumented reach to reduce disturbance associated with transport between capture and release and thereby increase the likelihood that crayfish would remain within range of the antenna network when re-introduced. Crayfish were not caught within the instrumented reach to avoid disturbing the crayfish being tracked, their physical environment and the tracking antennae. In total, 65 crayfish were tagged during the five-month observation period. The size of crayfish that were selected for tagging was standardised: only those with a carapace length of $55 \pm 5 \mathrm{~mm}$ were used, because this represented the mode and mean of caught, adult crayfish in the reach. In addition, a tag might be a burden to smaller individuals inhibiting their behaviour. Crayfish with obvious injury, such as the loss of limbs or antennae, were also deselected as this can affect their exploratory behaviour (Basil \& Sandeman, 2000; Koch et al., 2006). No berried females were caught.

Crayfish were caught by hand and placed in a plastic handling container. A single glassencapsulated PIT tag (12 mm long, $2 \mathrm{~mm}$ wide) was attached to the crayfish's cephalothorax as this causes little upset and results in a large percentage of tags remaining attached (Bubb et al., 2006). Cyanoacrylate was used to attach tags because it dries in minutes, limiting the time crayfish needed to be out of water. By minimising stress to the animal, this approach maximised the likelihood of natural behaviour upon release. Although cyanoacrylate weakens through time when submerged in water, it successfully attached tags to crayfish in aquaria experiments until crayfish moulted multiple months later. Given that the average time crayfish remained in the instrumented reach was 11 days (max. 38 days), the potential weakening of the adhesive is not seen as a limitation here. However, longer studies may require alternative strategies or the use of internal tags. Once the adhesive had set, the crayfish was submerged in a container for 15 minutes to check the tag was properly attached 
and the individual had not been adversely affected. Crayfish were then released into the river over antenna 4, due to its central location in the reach and because the presence of macrophyte cover prevented undue exposure during daylight hours. Crayfish are predominately nocturnal so activity during daylight hours on the day of release was considered likely to be inconsistent with natural behaviour and a direct result of tagging and release. Consequently, the movement of crayfish on the day of release was removed from the data-set and all future analysis.

Robinson et al. (2000) described a 'fright response' after release of radiotagged white-clawed crayfish (Austropotamobius pallipes), where individuals moved significantly more in the two days following release. However, they only quantified long-distance movements and, consequently, any 'fright response' on the scale observed in that study would have resulted in crayfish leaving the instrumented reach in this study. Indeed, of the 65 individuals tagged in this study, seven (11\%) left the reach within one day of being caught and released, which might indicate a 'fright response'. However, because substantial effort was made to minimise the disturbance during tagging, and 89\% of tagged crayfish remained in the reach, the loss of those leaving the study reach is not considered indicative of a major methodological problem.

\section{Statistical analysis}

Measures of the average distance moved by active crayfish were calculated for hourly and daily time periods and analysed in SPSS 19.0. Hourly averages were used when exploring the nocturnalism of crayfish, whereas daily averages were used when relating activity to environmental conditions. Levene’s tests indicated that the assumption of variance homogeneity was violated for comparisons of hourly and daily data, so Kruskall-Wallis tests were performed in order to ascertain significance levels. When daily-activity was related to 
continuous measures of water temperature and flow depth, regression analysis was used in SPSS 19.0. All assumptions were met for multiple linear regression; however, crayfish activity data were heteroscedastic when regressed on water temperature in simple linear models. Given that linear regression models are only used to demonstrate the lack of clear mean-based relations between environmental variables and activity, no further action was taken. In addition, quantile and median regression were performed on the data, providing a more robust regression analysis which is valid for heteroscedastic data. This was undertaken using the Quantreg package in R (Koenker, 2012). More information about quantile regression and its uses can be found in Cade \& Noon (2003).

Results

Environmental variables

The daily-averaged water temperature within the reach ranged from $6.8-17.1^{\circ} \mathrm{C}$ between 26 th June and the 22nd November 2009. The temperature declined steadily from 19th August to 22nd November 2009, giving a linear trend. During 38 years of gauged flow recording, the daily-averaged mean flow was $0.35 \mathrm{~m}^{3} \mathrm{~s}^{-1}$, the $95 \%$ exceedance $\left(\mathrm{Q}_{95}\right)$ was $0.068 \mathrm{~m}^{3} \mathrm{~s}^{-1}$ and the $10 \%$ exceedance $\left(\mathrm{Q}_{10}\right)$ was $0.729 \mathrm{~m}^{3} \mathrm{~s}^{-1}$. In most years, there were isolated high flow events in the summer and autumn, but these rarely exceeded $2 \mathrm{~m}^{3} \mathrm{~s}^{-1}$. Flow depth during the tracking period was variable (0.25-0.59 $\mathrm{m}$ at the pressure transducer), with a number of isolated high flow events, three of which were clustered in late July/early August. An extended period of low flow occurred throughout August and September 2009, producing a minimum recorded depth of $0.21 \mathrm{~m}$ over antenna 4 and $0.95 \mathrm{~m}$ over antenna 5. In October and November, the flow depth increased rapidly and remained relatively high throughout November. This trend in water depth was consistent with those recorded at the gauging 
station and is consistent with the 38-year average pattern, which implies that flow during the tracking period was typical for the river.

Nocturnalism of signal crayfish

Over the 150-day tracking period, 10,884 point locations were registered for 65 tagged crayfish. Crayfish moved preferentially during the hours of darkness, with less than $6 \%$ of all recorded movements occurring during daylight hours , here defined as occurring between sunset and sunrise (Figure 2). The nocturnal activity of crayfish is consistent through the months, with night-time activity always dominant over hours of sunlight. However, nocturnalism was weaker in the summer months, with significantly more daytime movements made in July in comparison to other months $(\mathrm{p}=0.039-0.042$; Figure 3$)$. Crayfish were most frequently active between 22:00-23:00 and 02:00-03:00, giving two peaks in night-time activity, which are statistically significant from both the preceding and subsequent hours ( $\mathrm{p}<$ 0.01 in all cases) (Figure 2). The percentage of movements in each hourly interval demonstrates the broad similarity of this pattern from month to month (Figure 3). However, the bimodal distribution of night-time activity, with its intervening decline around midnight, is less distinct in summer months. Male and female crayfish were both highly nocturnal and the percentage of movements made at night was statistically similar between sexes, equivalent to $90.6 \%$ for males and $89.4 \%$ for females.

The timing of peak activity changed from one month to another in the present study, occurring in the hour beginning 23:00 in July, 22:00 in August, September and October, and 21:00 in November . The sunset time shifted from 21:00 in July to 20:00 in August to 19:00 in September and 18:00 in October. Consequently, the shift of peak activity from July to November may reflect the increasingly earlier time of sunset in autumn months, however, 
disentangling this from changes in other relevant environmental and ecological/biological conditions is difficult.

Seasonal distribution of crayfish activity

There is a significant difference in crayfish activity levels between some months.

Significantly less activity took place in November in comparison with other months ( $\mathrm{p}<$ $0.001)$ and significantly more activity took place in September $(\mathrm{p}=0.04$; Figure 4$)$. Activity levels in other months were statistically similar $(\mathrm{p}=0.754)$. However, there was a great deal of day-to-day variability in activity throughout the tracking period. Levene's tests indicate that the variance of daily activity values was significantly different between months. The greatest range in daily activity occurred in September and the least in November.

There was no difference in the activity of male and female crayfish during the entire tracking period (ANOVA; $\mathrm{p}=0.78$ ) or within individual months, consistent with the findings of others (Guan \& Wiles, 1997; Kirjavainen \& Westman, 1999; Bubb et al., 2004). Females were generally less abundant than males, but a greater number of females were caught in August and September (47\% and 45\% females, respectively) in comparison to October and November (31\% and 17\%, respectively).

Time-series of activity data, flow depth and water temperature hint at environmental controls on crayfish activity and this is corroborated by the results, given above, which demonstrate significantly different activity levels between months (Figure 5). The relations between variables are linear, but there is a lot of scatter in all cases. Simple linear regression of both the measures of crayfish activity on water depth or water temperature are significant $(\mathrm{p}<$ 0.001). Amongst these, the strongest relations are between average distance moved and water 
depth, but in general the simple linear regression models provide poor explanatory power $\left(\mathrm{r}^{2}\right.$ lies between 0.08 and 0.42 ). Given that several environmental factors are likely to be simultaneously affecting crayfish behaviour, a more complex analysis was considered appropriate. Multiple linear regression of average distance moved using temperature and depth as independent variables was statistically significant $(\mathrm{p}<0.001)$ but, as with the simple regression analyses, the model had relatively weak explanatory power $\left(\mathrm{R}^{2}=0.46\right)$.

To further explore the relations between crayfish activity and water depth and temperature, the time-series were split into two sub-periods. The division was based on inspection of the distance moved data and the generation of best fitting least-squares curves for both subperiods. This division occurs at the beginning of September and marks the boundary between summer and autumn months (Figure 5). Autumn is characterised by a clear linear decline in activity and a decline in water temperature as winter approaches. The regression of distance moved against temperature in this sub-period has an $r^{2}$ of 0.53 . In contrast, during the summer months the regression coefficient is not significant, indicating no temporal trend (Figure 6).

Quantile regressions of the $5^{\text {th }}, 25^{\text {th }}, 50^{\text {th }}, 75^{\text {th }}$ and $95^{\text {th }}$ percentiles are all statistically significant where water depth is the independent variable ( $\mathrm{p}<0.001$ in all cases). The same holds true where water temperature is the independent variable, except in the case of the $95^{\text {th }}$ percentile, where the regression coefficient is not significant ( $p=0.06$; Figure 7$)$. The relations are linear in all cases, but general convergence of the regression curves indicates that crayfish activity became less variable as water-depth increased and temperature decreased, consistent with the observation that the variance of daily activity was less in November than September. The regression coefficient of the median $\left(50^{\text {th }}\right.$ percentile) relation 
between distance moved and depth indicates that crayfish moved, on average, $12.9 \mathrm{~m}$ less for every $0.1 \mathrm{~m}$ rise in water depth. This model also predicts that crayfish activity ceased in the River Bain when depth exceeded $0.52 \mathrm{~m}$ at the pressure transducer. Quantile regressions of movement on temperature indicate that, in general, activity increased with temperature. The median regression suggests that activity ceased when temperature fell below $5^{\circ} \mathrm{C}$ and increased with a rise in temperature above this threshold at a rate of $2.5 \mathrm{~m}^{\circ} \mathrm{C}^{-1}$.

\section{Discussion}

\section{Nocturnalism}

The timing of peak activity in the River Bain is consistent with other studies; for instance, Nyström (2005) found that signal crayfish were most active at dusk and Robinson et al. (2000) have shown that radio-tagged white-clawed crayfish were significantly more active between dusk and midnight (21:00-00:00) in comparison with any other time, including dawn (03:00-06:00). Unlike previous studies, crayfish in this reach of the River Bain remained active throughout the night. Guan \& Wiles (1998) studied the nocturnal foraging of signal crayfish in the River Ouse, England, using capture techniques. They found signal crayfish foraged between 17:00 and 01:00 in all seasons, much less between 01:00 and 09:00 and only occasionally between 09:00 and 17:00. In the present study, crayfish were, cumulatively, more active between 01:00 and 09:00 than between 17:00 and 01:00, suggesting that, in this small stream, crayfish only had a weak preference for a particular period during the night when conducting their activities. In fact, many of the months had two peaks of activity during the night - at and just after dusk and then again at 02:00. The reasons for this are currently not known, but it might reflect an initial burst of activity at dusk, perhaps associated with foraging, followed by a secondary burst of activity later, when, perhaps, they had begun to seek refuge before dawn. 
Crayfish were highly nocturnal, with little daytime activity occurring over the 150 days of study. They are visual predators, but are nocturnal in their native range due to the threat of being detected by other visual predators. Where crayfish have invaded, such as in the British Isles, the threat of predation is likely to be much reduced and, consequently, it might be beneficial for populations of crayfish to adopt daytime activity. Some authors have identified invasive crayfish populations as being at least partially active in daylight hours (i.e. Guan \& Wiles, 1998) and the present authors have observed daylight activity in other English rivers. It may be that the River Bain is characterised by a suite of conditions that make daytime movement less favourable. For example, it is shallow through most of the instrumented reach (mean depth of $0.45 \mathrm{~m}$ during the tracking period), that crayfish are more vulnerable to visual terrestrial predators, such as wading birds. However, if this were the case, it is surprising that nocturnalism was strongest in winter, with more daytime movements occurring in July and August when, presumably, crayfish are most exposed because of bright sunlight and low flow depths. Gherardi et al. (2000) found that invasive Red Swamp crayfish (Procambarus clarkii) were nocturnal throughout the year, with the exception of the spring, when they made significantly more daylight movements. Together with the data presented here, this suggests that nocturnalism in invasive crayfish may be variable within and between rivers due to the changing hours of darkness and prevailing environmental conditions.

\section{Controls on crayfish activity} PIT-tagged signal crayfish were highly active within the instrumented reach during the 150day tracking period. However, it is apparent that levels of crayfish activity changed through time, implying that some periods were favoured by crayfish more than others. It should be noted that 'activity' is defined in this study as a movement greater than $0.29 \mathrm{~m}$, which may 
represent foraging for food, escaping a predator or competitor, or exploring the environment in search of new resources. They might be active in other ways, for instance, feeding or grooming, but these would not be recorded in this study because two spatially separated antennae would not be triggered by these comparatively sedentary activities.

There is a significant difference between crayfish activity levels each month, with less activity in November and more in September than in other months. As September was warm with relatively low flow depths (average $12.9^{\circ} \mathrm{C}, 0.30 \mathrm{~m}$ ) and November was cold with high flows $\left(8.6^{\circ} \mathrm{C}, 0.49 \mathrm{~m}\right)$, we can hypothesize that these environmental conditions affected activity. In addition, signal crayfish breed in autumn, with females protecting their eggs by carrying them under their tails until May. This may explain the increased activity of crayfish in September and the decline in the number of females caught in later months. Evidence from other studies supports the hypothesis that crayfish activity is limited by temperature (Gherardi et al., 2002; Bubb et al., 2002). Bubb et al. (2002) found that crayfish stopped making longdistance movements when water temperature dropped to an average of $4.2^{\circ} \mathrm{C}\left(\mathrm{S} \cdot \mathrm{D} .=1.3^{\circ} \mathrm{C}\right)$. In the River Bain, an extrapolation of the quantile regression model of median values predicts the complete cessation of movement at $5^{\circ} \mathrm{C}$. Previous studies have also demonstrated that high flows can both displace and cause mortality in several crayfish species (Momot, 1966; Robinson et al., 2000; Royo et al., 2002), including signal crayfish (Light 2003). However, Bubb et al. (2002; 2004) found, using radio-telemetry, that signal crayfish were not entrained by high flows because, presumably, they sheltered in burrows or in stable areas of substrate. Light (2003) suggested that signal crayfish shelter in deep pools or ponds during storm flows and re-emerge when flow levels recede. Our observations support these speculations, because crayfish rarely moved during high flow events, but always re-emerged afterwards. 
Statistical relationships with threshold conditions

There is apparent incongruity between the observed impact of flow characteristics and water temperature on crayfish activity and the weak levels of explanation given by the simple, least-squares regression models. This apparent incongruence is not limited to this study. For example, Bubb et al. (2004) found that the daily movement of radiotagged signal crayfish was significantly correlated with water temperature, but derived a relatively low $\mathrm{r}^{2}$ of 0.24 . Such low coefficients of determination reflect the heteroscedasticity of the data sets, specifically the wedge-shaped increase in variance when plotted against temperature and the decrease in variance when plotted against depth. This suggests that simple models of this type are not appropriate. Instead, quantile regression models appear to be more useful here, as they are for other relations between ecological and environmental variables where there is evidence of limiting conditions (Lancaster \& Belyea, 2006). This is largely because a favourable condition does not necessitate increased activity of an animal as is implied by least-square regression models but, instead, only provides the opportunity for increased activity, which animals may or may not decide to undertake based on other environmental and ecological conditions.

Nested hierarchy of environmental controls Variability in crayfish activity is apparent within the data over a large range of time-scales, from minutes to months. On the basis of these results, it is hypothesised that the activity of crayfish, and all aquatic animals, is controlled by a range of biological and environmental processes that act as a nested hierarchy, each limiting activity at different time-scales (Figure 8). This is similar to the spatially nested hierarchy of habitat subsystems in rivers that has been proposed by Frissell et al. (1986). As a result, the significance of an environmental factor to animal activity will be at least partially dependent on the temporal scale at which 
activity is measured. Here, it is argued that temperature is of significance at the longest timescales (season, year) because there is a clear annual trend in the activity of crayfish and this broadly parallels the temperature time-series. Therefore, temperature is likely to be noted as significant only when long data-series are recorded, covering many months and, preferably, several years. In addition, when temperature is relatively constant, changes in activity in response to small fluctuations in temperature may be undetectable; they may also be masked by the impact of other factors (e.g. flight because of fright) that influence levels of activity associated with smaller time-scales. This is reflected in the data, where regression analyses provide improved predictive models of behaviour in autumn, when temperature was changing, than in summer, when the temperature was both high and comparatively constant.

At smaller time-scales of weeks to days, flow depth appears to be of most significance. This may also explain why depth provided the strongest relation with activity over the time-scale studied here. It is clear that when the flow is high, crayfish cease moving even if other conditions are favourable. This is likely to be the case because changes in water depth in rivers are likely to manifest over many hours to days, even in rivers with flashy regimes. At an hourly scale, light levels have the largest impact on activity, with crayfish in the River Bain generally only moving in darkness. At smaller scales (seconds-hours) where temperature, depth and light levels are essentially stable, it is likely that conspecific and interspecific interactions (e.g. fighting, fleeing) and biological imperatives (e.g. feeding) dominate levels of crayfish activity, although consideration of these effects was not one of the aims of this study and we did not measure them. These smaller-scale biological and ecological controls are superimposed on larger scale trends, generating 'noise' in the recorded data. In addition, there are ecological and biological factors that operate across the longer timescales from years to days (e.g. food availability, predator activity, mating periods) 
that are also likely to affect crayfish activity levels. Together with the high frequency noise noted above, this biological/ecological control is likely to be, at least, partly responsible for the relatively weak explanatory power of mean-based, least-squares regression models with only environmental independent variables.

Further interactions complicate the response of animals to environmental changes, making it yet more difficult to disentangle patterns of cause and effect. So, for example, upper-rung variables, representing the largest-scale controls on activity, can nullify the influence of lower-rung variables when they impose conditions that are not conducive of activity (i.e. when they are limiting). For example, if the temperature is cold enough to limit animal activity, favourable conditions of flow depth do not lure the animal into increased activity. However, the opposite can obtain. So, for example, the presence of a predator (a lower-rung variable) is likely to prevent animal activity when all other conditions (e.g. temperature and water-depth) are favourable. The relative position of controlling variables in the hierarchy may provide useful information about their significance for activity, such that testing and extending the conceptual model presented in Figure 8, will provide a useful avenue of research. It should be noted, however, that the significance of each environmental variable is likely to be species- and context-dependent and its hierarchical significance may differ from one river to another.

\section{Conclusions}

The environmental characteristics monitored in this study are shown to have acted as controls on crayfish activity. They form a nested hierarchy, causing activity to be highly variable over a range of time-scales and this restricts the value of mean-based regression models as tools explaining and quantifying the impact of controls on activity. Instead, quantile regression 
provided a useful, alternative tool for identifying the conditions determining and limiting crayfish activity.

There is evidence that environmental factors affect the extent of nocturnalism in invasive crayfish, because the proportion of daytime movements was shown to be significantly greater in summer months than in autumn months. Quantile regression analysis suggests that crayfish are tolerant of a wide range of flows, but are most active when low flows coincide with periods of high water temperature. Analysis also suggests that signal crayfish are sensitive to water temperature and activity is shown to decline substantially as water temperature decreases in autumn. However, given the variability in nocturnalism that has been reported for different rivers, it is suggested that environmental conditions, such as flow depth, speed and temperature, may have different impacts both in different rivers and from reach to reach within the same river, reflecting the variable significance of other factors, such as the ability to hide from predators. This is important for understanding the invasion of non-native crayfish and attempting to manage their spread throughout the river network.

\section{Acknowledgements}

We would like to thank: Kevin Wallis for allowing us to use the field site; Paul Wood for his help throughout this project; Stuart Ashby and Barry Kenny for help with equipment; and Mary Johnson, Richard Gravelle, Tom Worrell and Andrew Pledger for help with field work. During this study, MFJ was in receipt of a Loughborough University Postgraduate Studentship.

References 
Almeida, D., A. Ellis, J. England \& G.H. Copp. 2013. Time-series analysis of native and nonnative crayfish dynamics in the Thames River Basin (south-eastern England). Aquatic Conservation: Marine and Freshwater Ecosystems. Early view. DOI: 10.1002/aqc.2366 Basil, J. \& D. Sandeman, 2000. Crayfish (Cherax destructor) use tactile cues to detect and learn topographical changes in their environment. Ethology 106: 247-259.

Bubb, D.H., M.C. Lucas \& T.J. Thom, 2002. Winter movements and activity of signal crayfish Pacifastacus leniusculus in an upland river, determined by radio telemetry. Hydrobiologia 483: 111-119.

Bubb, D.H., T.J. Thom \& M.C. Lucas, 2004. Movement and dispersal of the invasive signal crayfish Pacifastacus leniusculus in upland rivers. Freshwater Biology 49: 357-368.

Bubb, D.H., T.J. Thom \& M.C. Lucas, 2006b. Movement patterns of the invasive signal crayfish determined by PIT telemetry. Canadian Journal of Zoology 84: 1202-1209.

Cade, B.S. \& B.R. Noon, 2003. A gentle introduction to quantile regression for ecologists. Frontiers in Ecology and the Environment 1: 412-420.

Crawford, L., W.E. Yeomans \& C.E. Adams, 2006. The impact of introduced signal crayfish Pacifastacus leniusculus on stream invertebrate communities. Aquatic Conservation: Marine and Freshwater Ecosystems 16: 611-621.

Gherardi, F., S. Barbaresi \& G. Salvi, 2006. Spatial and temporal patterns in the movement of Procambarus clarkii, an invasive species. Aquatic Sciences 62: 179-193.

Gherardi, F., S. Barbaresi \& F. Villanelli, 1998. Movement patterns of the white-clawed crayfish Austropotamobius pallipes, in a Tuscan Stream. Journal of Freshwater Ecology 134: 413-424.

Gherardi, F., E. Tricarico \& M. Iljeu, 2002. Movement patterns of the invasive crayfish, Procambarus clarkii, in a temporary stream of southern Portugal. Ethology, Ecology and Evolution 14: 183-197. 
Gherardi, F., S. Barbaresi \& G. Salvi, 2000. Spatial and temporal patterns in the movement of Procambarus clarkii, an invasive crayfish. Aquatic Science 62: 179-193.

Gibbins, J.W. \& K.M. Andrews, 2004. PIT Tagging: Simple Technology at Its Best. Bioscience 54: 447-454.

Guan, R-Z. 1994. Burrowing behaviour of signal crayfish, Pacifastacus leniusculus (Dana), in the River Great Ouse, England. Freshwater Forum 4: 155-168.

Guan, R-Z. \& P.R. Wiles, 1997. Ecological impact of introduced crayfish on benthic fishes in a British lowland river. Conservation Biology 11: 641-647.

Guan, R-Z. \& P.R. Wiles, 1998. Feeding ecology of the signal crayfish Pacifastacus leniusculus in a British lowland river. Aquaculture 169: 177-193.

Harvey, G., T.P. Moorhouse, N.J. Clifford, A. Henshaw, M.F. Johnson, D.W. MacDonald, I. Reid, \& S.P. Rice, 2011. Evaluating the role of invasive aquatic species as drivers of fine sediment-related river management problems: the case of the signal crayfish (Pacifastacus leniusculus). Progress in Physical Geography 35: 517-533.

Harvey, G., A. Henshaw, T. Moorhouse, N. Clifford, H. Holah, J. Grey \& D. MacDonald. In press. Signal crayfish as drivers of fine sediment dynamics in rivers: field and laboratory evidence. Earth Surface Processes and Landforms

Holdich, D.M., W.D. Rogers, \& J.D. Reynolds 1999. Native and alien crayfish in the British Isles. In Gherardi, F. \& D.M. Holdich (eds), Crayfish in Europe as Alien Species: How to Make the Best of a Bad Situation? A.A. Balkema, Rotterdam, The Netherlands: 221-236. Johnson, M.F., S.P. Rice \& I. Reid, 2010. Topographic disturbance of subaqueous gravel substrates by signal crayfish (Pacifastacus leniusculus). Geomorphology 123: 269-278. Johnson, M.F., S.P. Rice \& I. Reid, 2011. Increase in coarse sediment transport associated with disturbance of gravel river beds by signal crayfish (Pacifastacus leniusculus). Earth Surface Processes and Landforms 36: 1680-1692. 
Kirjavainen, J. \& K. Westman, 1999. Natural history and development of the introduced signal crayfish, Pacifastacus leniusculus, in a small, isolated Finnish lake, from 1968 to 1993. Aquatic Living Resources 12: 387-401.

Koch, L.M., B.W. Patullo \& D.L. Macmillan, 2006. Exploring with damaged antennae: do crayfish compensate for injuries? The Journal of Experimental Biology 209: 3226-3233. Koenker, R., 2012. Quantile regression in R: A vignette. http://cran.rproject.org/web/packages/quantreg/vignettes/rq.pdf (accessed March 2013) Lancaster, J. \& L.R. Belyea, 2006. Defining the limits to local density: alternative views of abundance-environment relationships. Freshwater Biology 51: 783-796.

Light, T., 2003. Success and failure in a lotic crayfish invasion: the roles of hydrologic variability and habitat alteration. Freshwater Biology 48: 1886-1897.

Lodge, D.M., R.A. Stein, K.M. Brown, A.P. Covich, C. Brönmark, J.E. Garvey \& S.P. Klosiewski, 1998. Predicting impact of freshwater exotic species on native biodiversity: challenges in spatial scaling. Australian Journal of Ecology 23: 53-67. Machino, Y. \& D.M. Holdich, 2005. Distribution of crayfish in Europe and adjacent countries: updates and comments. Freshwater Crayfish 15: 292-323.

Momot, W.T., 1995. Redefining the role of crayfish in aquatic ecosystems. Reviews in Fisheries Science 3: 33-63.

Momot, W.T., 1966. Upstream movement of crayfish in an intermittent Oklahoma stream. American Midland Naturalist 75: 150-159.

Nyström P., 2005. Non-lethal predator effects on the performance of a native and an exotic crayfish species. Freshwater Biology 50: 1938-1949.

Nyström, P. \& J.A. Strand, 1996. Grazing by a native and an exotic crayfish on aquatic macrophytes. Freshwater Biology 36: 673-682. 
Nyström P, C. Brönmark \& W. Granéli, 1996. Patterns in benthic food webs: a role for omnivorous crayfish? Freshwater Biology 36: 631-646

Robinson, C.A., T.J. Thom, M.C. Lucas, 2000. Ranging behaviour of a large freshwater invertebrate, the white-clawed crayfish Austropotamobius pallipes. Freshwater Biology 44: 509-521.

Royo, F., G. Gonzalez-Cienfuegos \& J.L. Muzguiz, 2002. Preliminary observation of occasional mortality in the population of freshwater crayfish in the Picos de Europa (Asturias, Spain). Bulletin Francais de la Pêche et de la Pisciculture 367: 935-941.

Schofield, K.A., C.M. Pringle, J.L. Meyer \& A.B. Sutherland, 2001. The importance of crayfish in the breakdown of rhododendron leaf litter. Freshwater Biology 46: 1191-1204. Schütze, S., H. Stein \& O. Born, 1999. Radio telemetry observations on migration and activity patterns of restocked noble crayfish Astacus astacus (L.) in the small river Sempt, North-East of Munich, Germany. Freshwater Crayfish 12: 688-695.

Stenroth, P. \& P. Nyström, 2003. Exotic crayfish in a brown water stream: effects on juvenile trout, invertebrates and algae. Freshwater Biology 48: 466-475.

Usio, N., M. Konishi \& S. Nakano, 2001. Species displacement between an introduced and a 'vulnerable' crayfish: the role of aggressive interactions and shelter competition. Biological Invasions 3: 179-185.

Vorburger, C. \& G. Ribi, 1999. Aggression and competition for shelter between a native and an introduced crayfish in Europe. Freshwater Biology 42: 111-119. 
Figure legend

Figure 1: Map of the instrumented reach of the River Bain, showing antenna locations.

Channel-bed contours relate to a local datum.

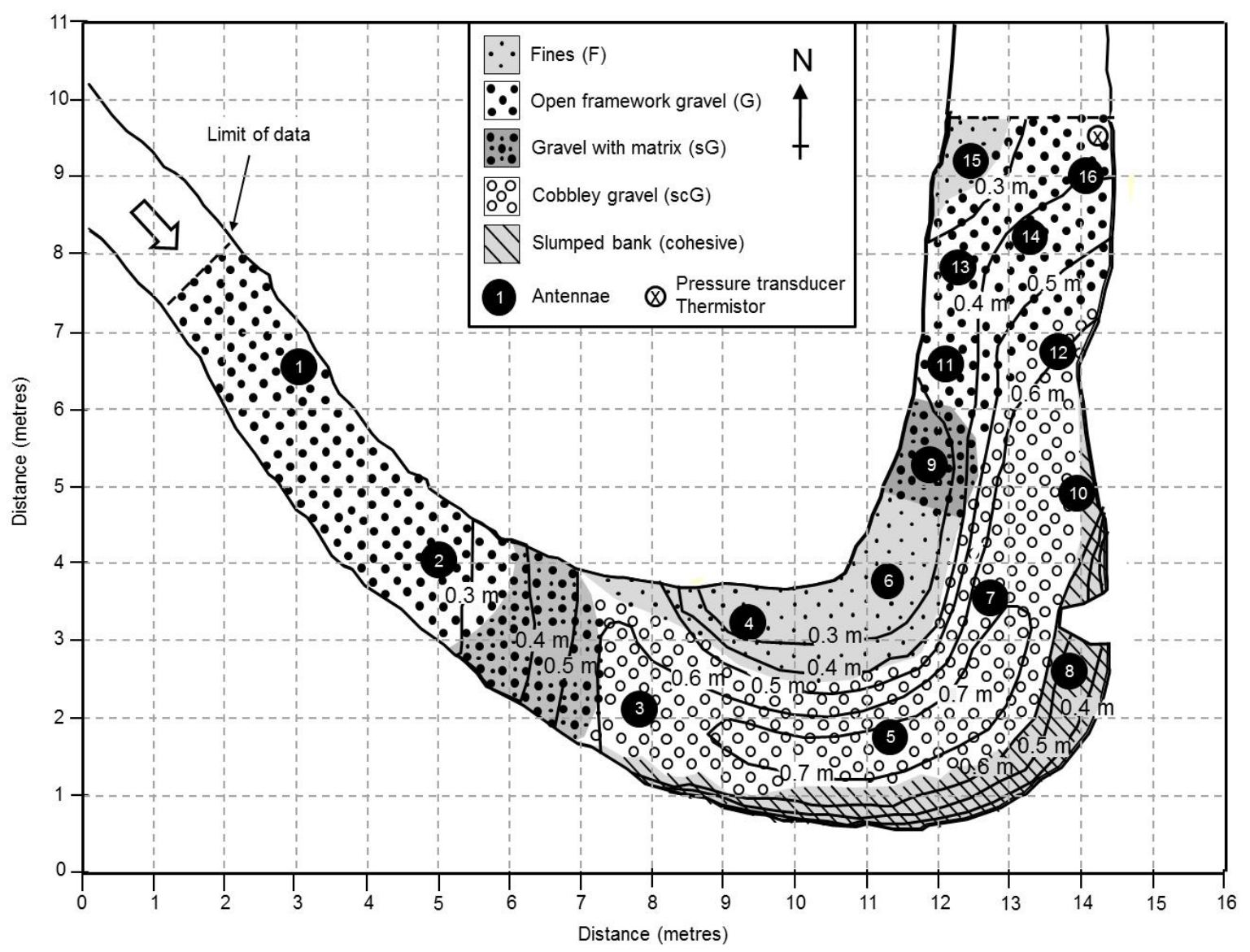


Figure 2: The percentage of total distance moved by tagged crayfish during each hour of the day between $22^{\text {nd }}$ June and $22^{\text {nd }}$ November 2009.

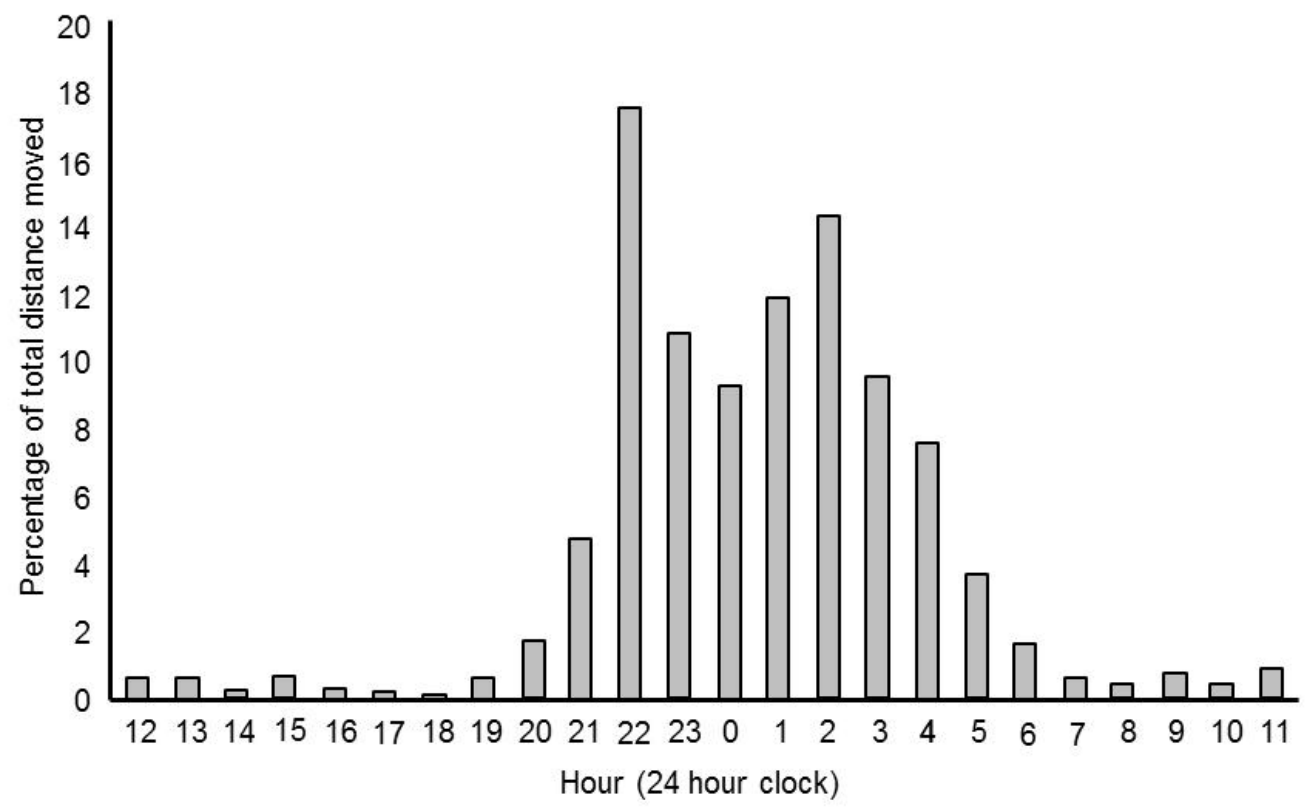


Figure 3: a) The total distance moved by tagged crayfish and b) the percentage of the total distance moved by tagged crayfish in each hour of the day, in each month, July-November 2009.

a)
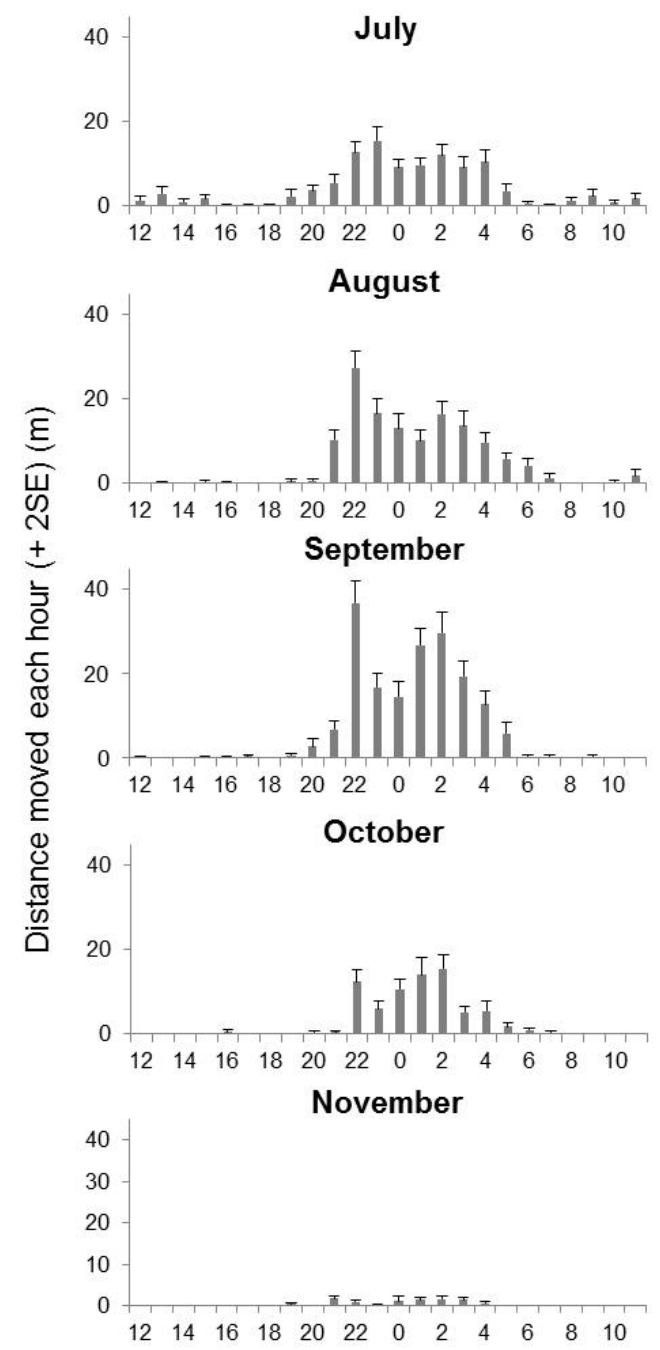

Hour b)

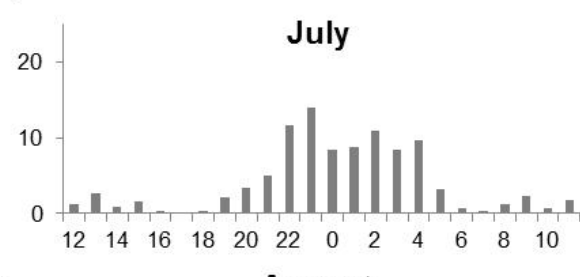

의 August
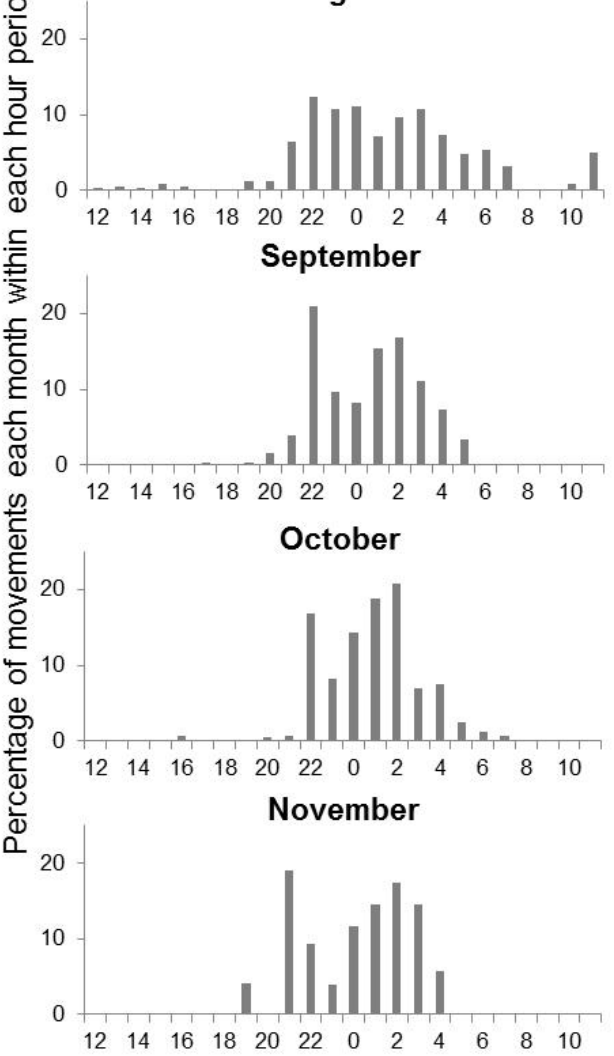

Hour 
Figure 4: The average distance (+2 SD) moved by crayfish each month of summer and autumn 2009. Letters indicate significant statistical groupings based on Kruskall-Wallis with Bonferroni corrected Mann-Whitney post-hoc tests

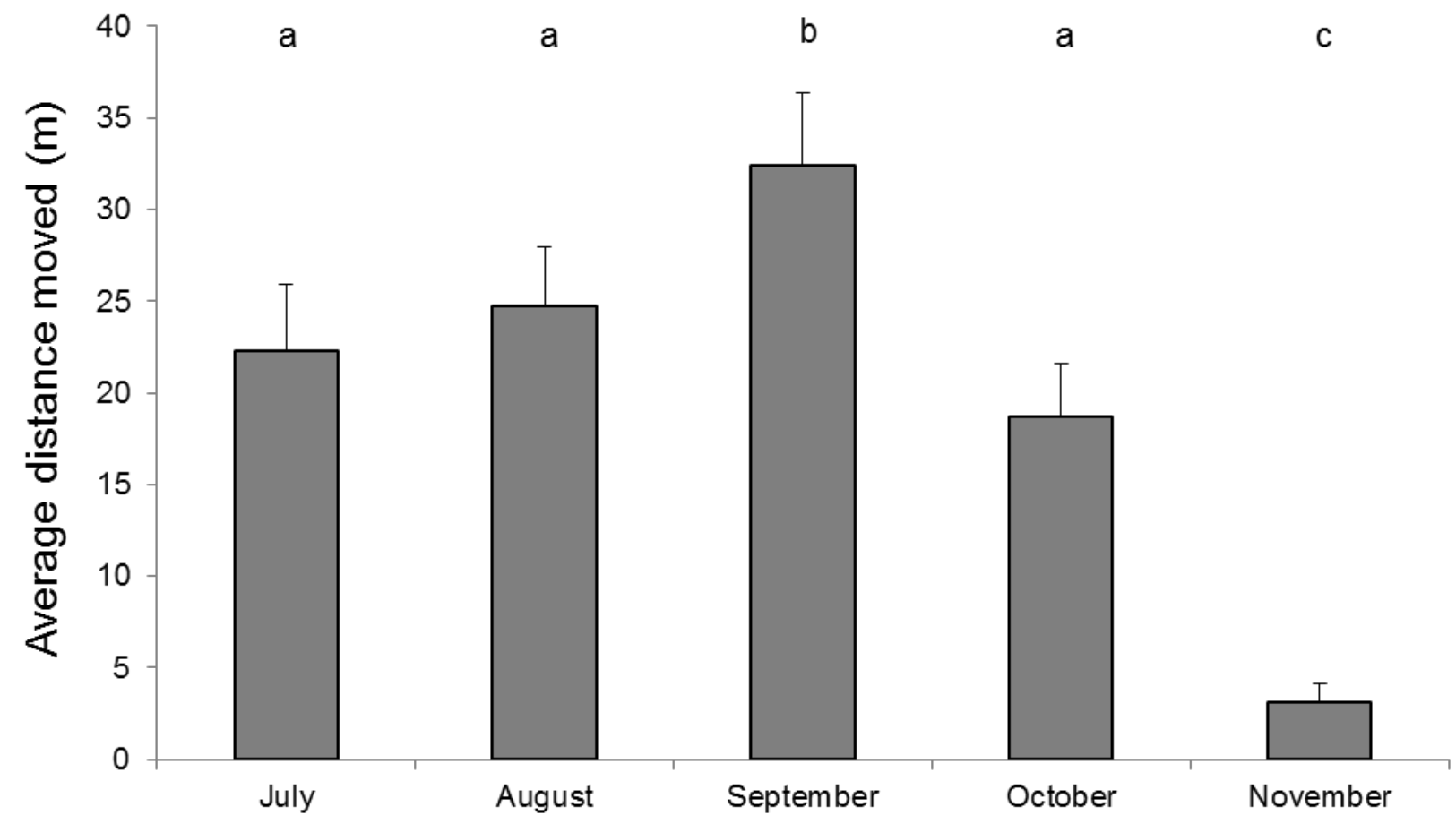


Figure 5: Time-series of crayfish activity (black line), water temperature (pecked line) and flow depth (grey line). Vertical pecked line separates the time-series into two broad subperiods based on obtaining the best-fit of the two regression lines describing crayfish activity with time.

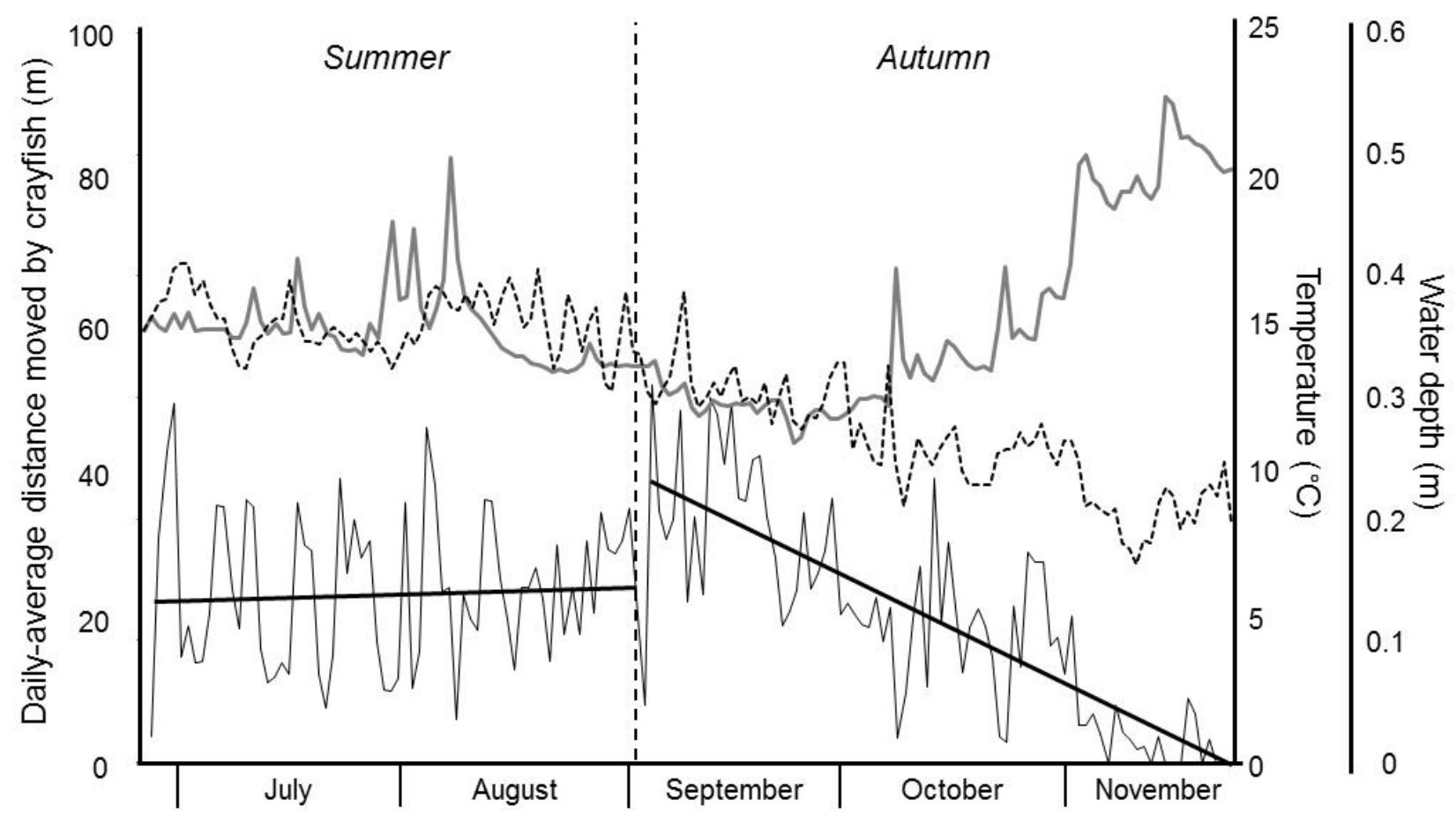


Figure 6: a) Time-series of the daily-averaged distance moved by crayfish (solid line) and the water temperature (pecked line) in (a) summer and (c) autumn. Best-fit lines represent the regression of each variable on time. Scatter-plots of daily-averaged distance moved by crayfish versus water temperature for (b) summer and (d) winter.

a)

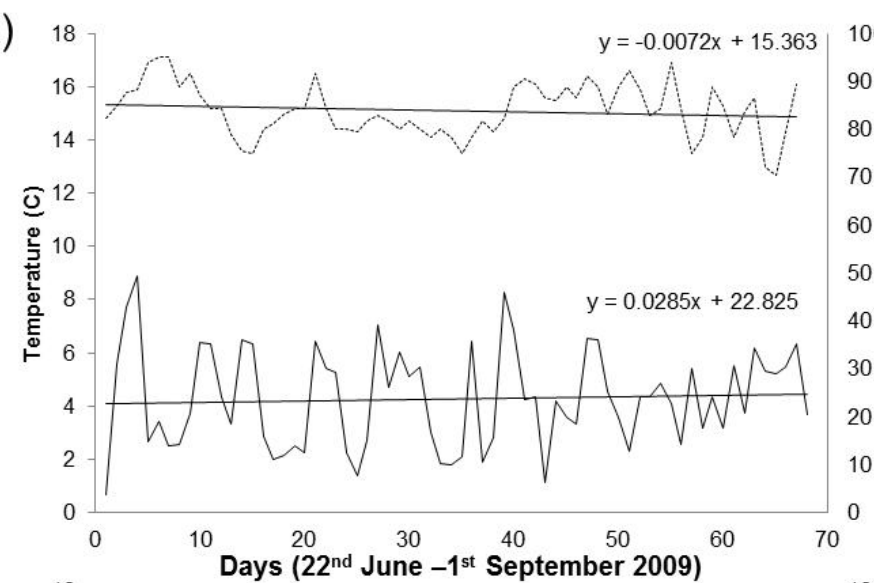

c)

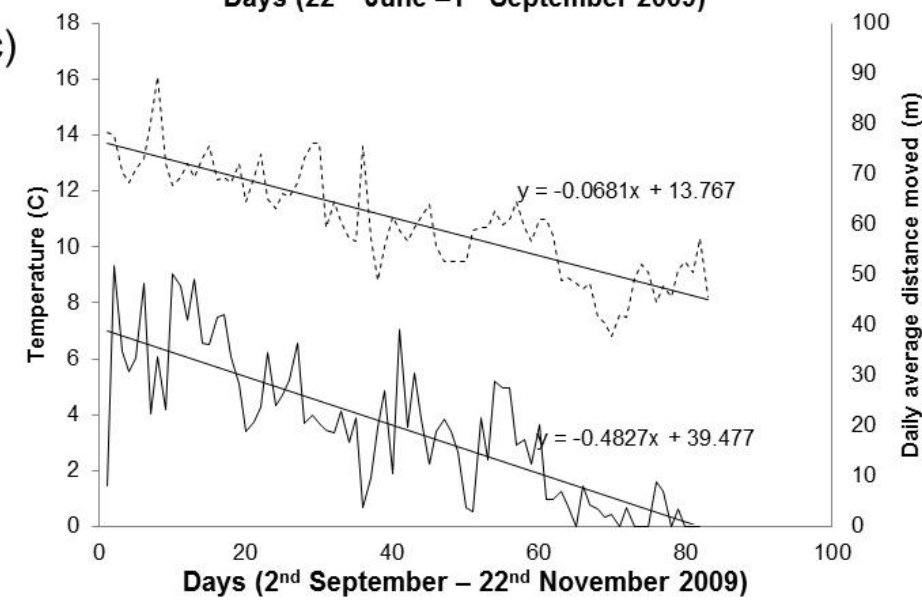

b)

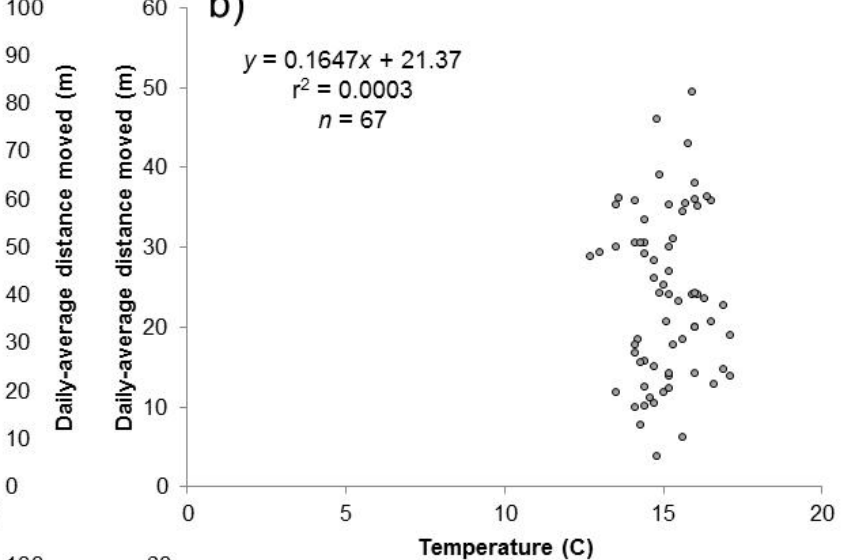

d)

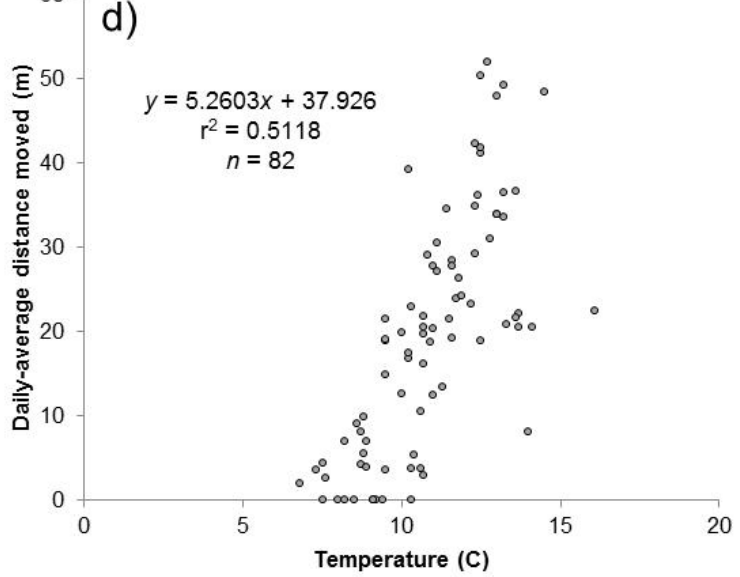


Figure 7: Scatterplot of daily-averaged distance moved by crayfish versus (a) water temperature and (b) water depth with quantile regressions for the $5^{\text {th }}, 25^{\text {th }}, 50^{\text {th }}$ (median), $75^{\text {th }}$ and $95^{\text {th }}$ percentiles.

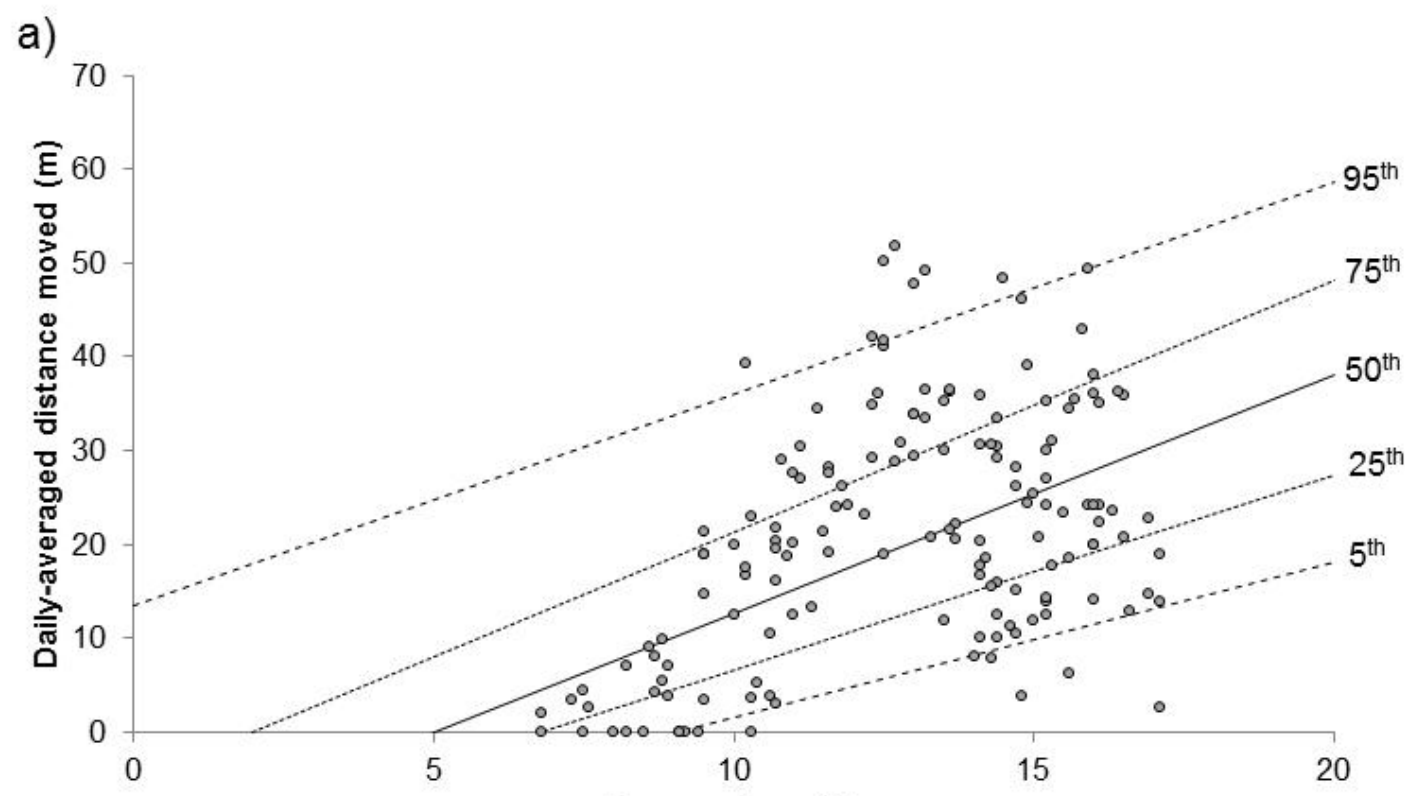

b)

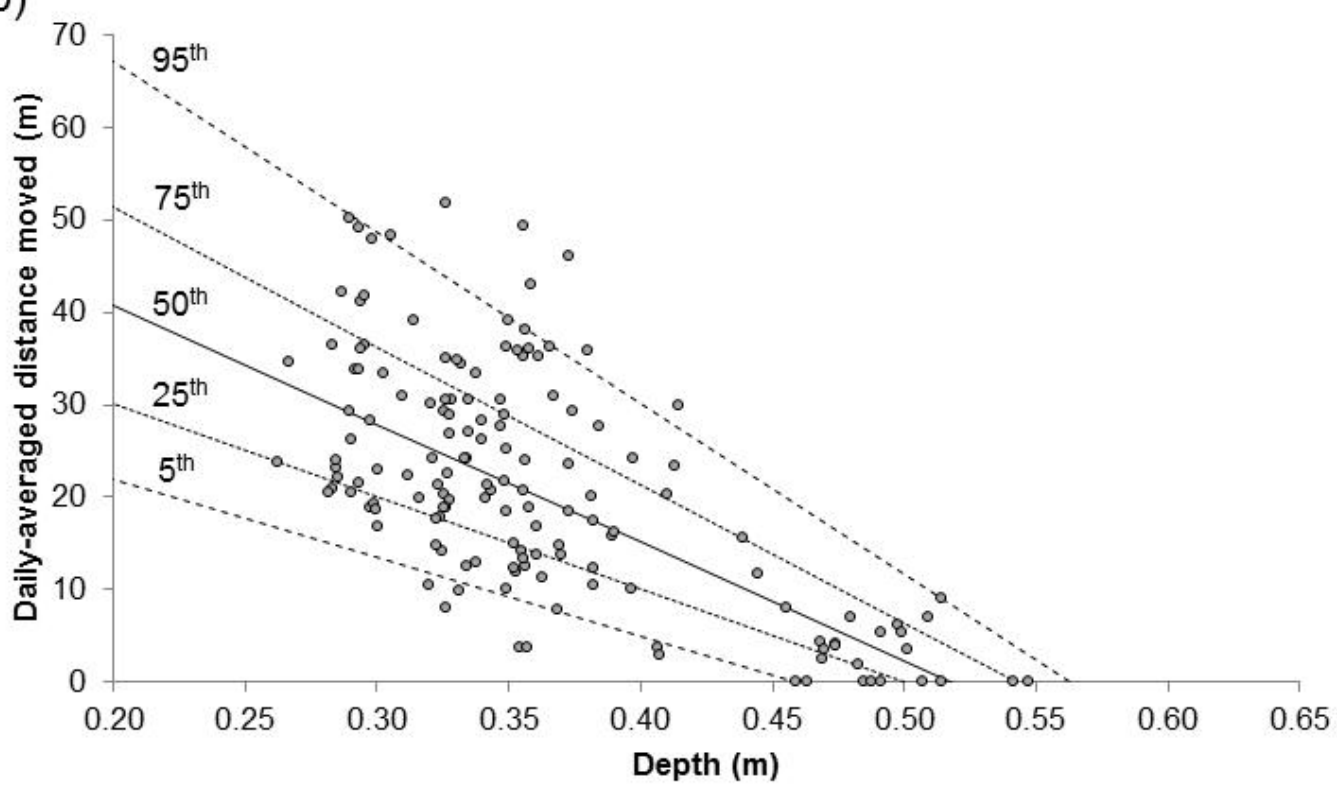


Figure 8: A theoretical model of the nested hierarchy of environmental controls on crayfish activity (y-axis); the significance of each control is dependent on the temporal scale.

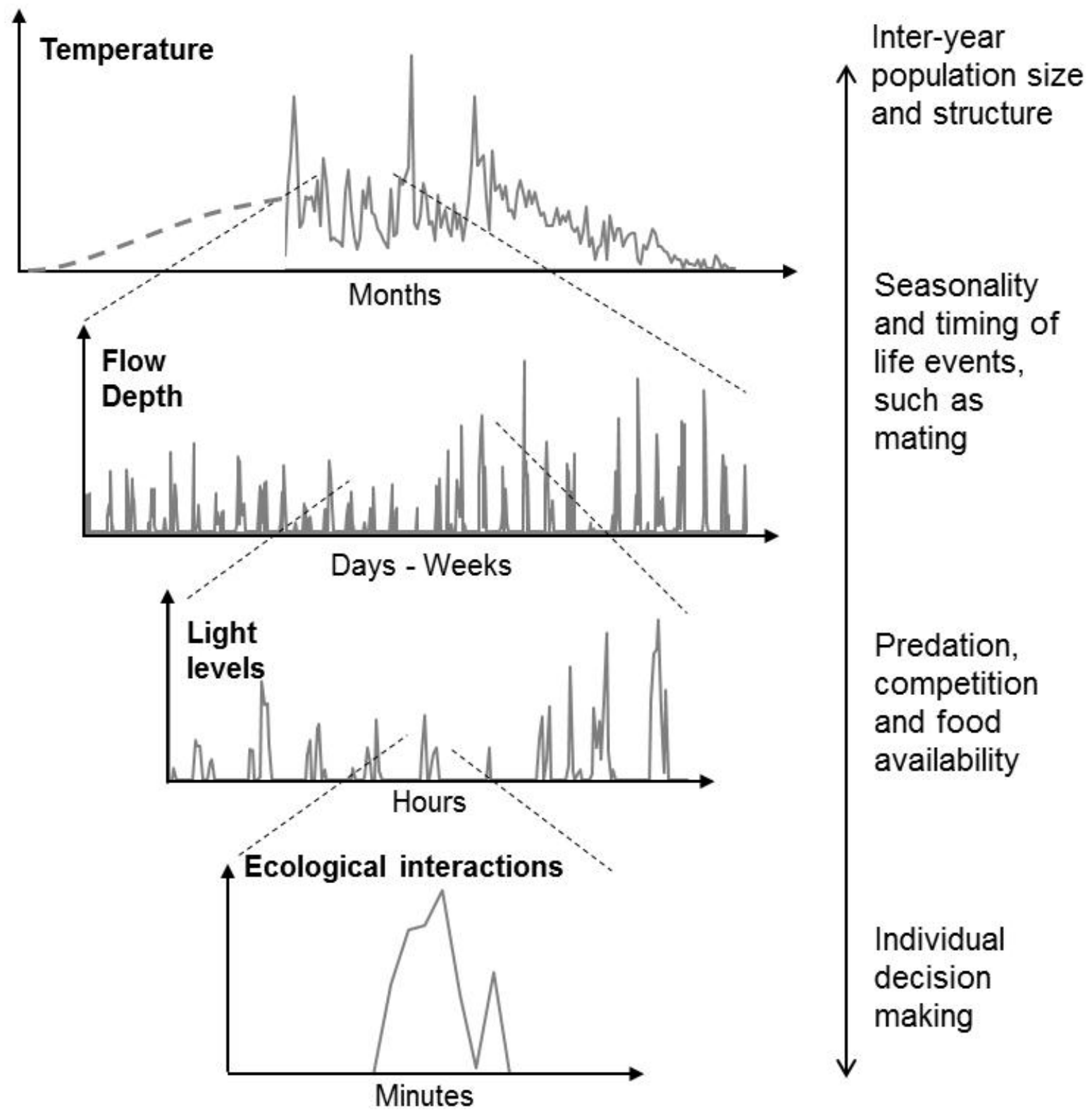

